\title{
UM MAGMATISMO BIMODAL ARQUEANO NO ÂMBITO DOS COMPLEXOS METAMÓRFICOS DO QUADRILÁTERO FERRÍFERO E SUAS IMPLICAÇÔES TECTÔNICAS
}

\author{
M.A.Carneiro ${ }^{1}$, H.Jordt-Evangelista ${ }^{1}$, W.Teixeira ${ }^{2}$
}

Dentre as várias suites do Complexo Metamórfico Bonfim, que constitui um dos fragmentos siálicos do Quadrilátero Ferrífero, destaca-se uma associação petrográfica formada por metamafitos tholeíticos - Anfibolitos Candeias - que são intrusivos em magmatitos cálcio-alcalinos - Tonalitos Samambaia - (Carneiro, 1992; Carneiro \& Teixeira, 1993), que, por sua vez, apresentam texturas ígneas preservadas (Carneiro et al., 1994). Estas duas suítes não apresentam termos petrográficos intermediários entre si, tratando-se, portanto, de um magmatismo tipicamente bimodal, onde os Anfibolitos Candeias e os Tonalitos Samambaia constituem dois grupos quimicamente distintos. 0 caráter não cogenético deste magmatismo está, de certa forma, confirmado pelos dois agrupamentos distintos de idades Sm-Nd (TDM). Enquanto os Tonalitos Samambaia mostram idades Sm-Nd da ordem de 2940 e $2800 \mathrm{Ma}$, os Anfibolitos Candeias têm uma idade da ordem de $2780 \mathrm{Ma}$ (Carneiro et al., 1995; Carneiro et al., 1996; Teixeira et al., 1996). Ainda com relação à geocronologia destas suites, os zircões e as titanitas dos Tonalitos Samambaia têm uma mesma idade U-Pb de 2780+3/-2 Ma (Machado \& Carneiro, 1992). Finalmente, os Anfibolitos Candeias apresentam idade K-Ar em anfibólio na ordem de $1707 \pm 64 \mathrm{Ma}$, enquanto que os Tonalitos Samambaia têm idades K-Ar em biotita variando de 1166 a $715 \mathrm{Ma}$ (Carneiro, 1992). A concordância entre as idades U-Pb de zircão e titanita dos Tonalitos Samambaia é, por si só, um fato curioso. Pois, caso estas suites tivessem sido submetidas a um regime metamórfico de fácies anfibolito em épocas posteriores ao Arqueano como, por exemplo, no decorrer do Evento Transamazônico, as titanitas teriam sido reequilibradas isotopicamente. Todavia, verifica-se que a principal transformação metamórfica nos Tonalitos Samambaia foi a saussuritização dos seus feldspatos. Esta saussuritização deu-se preferencialmente ao longo de superficies anastomosadas e mais ou menos planares, onde também ocorreram transformações texturais como, por exemplo, a recristalização dinâmica de biotitas e quartzo. Estas superficies, que canalizaram o fluxo dos fluidos aquosos indispensáveis às reações metamórficas, são zonas de alto strain onde se concentrou a deformação. A saussuritização de feldspatos é uma reação do tipo:

4 Ca-plagioclásio $+\mathrm{K}$-feldspato $+\mathrm{H}_{2} \mathrm{O}=$ moscovita +2 zoisita +2 quartzo.

A temperatura de equilibrio desta reação fica em torno de $\pm 520^{\circ} \mathrm{C}$ para uma $\mathrm{P}$ de $4 \mathrm{kbar}$ (Braun, 1974), que corresponde à transição da fácies xisto verde para a fácies anfibolito. A forte influência de fluidos aquosos e o caráter não penetrativo das transformações metamórficas no Quadrilátero Ferrifero também foram verificadas em outros corpos ígneos, tal como no Granito Mamona (Jordt-Evangelista et al., 1993a, b). Já no caso dos Anfibolitos Candeias verifica-se que o metamorfismo, que foi da fácies xisto verde alto a anfibolito baixo,

\footnotetext{
${ }^{1}$ DG, Escola de Minas, Universidade Federal de Ouro Preto.

${ }^{2}$ DGG, Instituto de Geociências, Universidade de São Paulo.
} 
teve uma atuação muito mais eficaz do que nos tonalitos, pois as transformações mineralógicas de saussuritização dos plagioclásios e de anfibolitização dos piroxênios magmáticos foram quase que completas, restando raramente texturas ou minerais primários. Conforme ressaltado por Rumble (1989), o controle estrutural e as propriedades mecânicas das rochas são fatores de suma importância no controle do fluxo de fluidos. Fraturas, por exemplo, que são as descontinuidades estruturais por onde magmas máficos ascendem através da crosta para constituir diques, tendem a focalizar o fluxo de fluidos. Portanto, o protólito dos Anfibolitos Candeias foi metamorfoseado de modo muito mais homogêneo, do que os Tonalitos Samambaia, porque certamente o acesso dos fluidos aquosos a estas rochas de dique foi muito mais fácil do que ao granitóide maciço. Assim sendo, é possível concluir que: i) a transformação metamórfica ocorrida nos Tonalitos Samambaia e Anfibolitos Candeias pode ser um processo restrito e localizado ao longo das zonas de fraqueza ou ainda segundo os próprios planos de descontinuidade crustal por onde o magma tholeiítico, responsável pela geração dos protólitos dos Anfibolitos Candeias, ascendeu crosta acima; ii) este metamorfismo, que se situa no limite entre a fácies xisto verde alto a anfibolito, deve ter ocorrido logo após a cristalização magmática destas duas suítes, caso contrário o sistema isotópico das titanitas teria sido reequilibrado mais tardiamente; iii) finalmente, fica claro que a atuação do Evento Transamazônico, no âmbito do Complexo Metamórfico Bonfim e, por conseguinte, no Quadrilátero Ferrifero, tem um caráter heterogêneo do ponto de vista de seu regime tectono-metamórfico. Daí a variação da intensidade e/ou do grau metamórfico nas suas diferentes regiões.

\section{Referências Bibliográficas}

BRAUN, E. (1974) Mikrosondenuntersuchungen von Saussuriten in Abhängigkeit vom Metamorphosegrad und vom geochemischen Milieu. Contributions of Mineralogy and Petrology, v.46, p.301-327.

CARNEIRO, M.A. (1992) O Complexo Metamórfico Bonfim Setentrional (Quadrilátero Ferrifero, Minas Gerais): Litoestratigrafia e Evolução Geológica de um Segmento de Crosta Continental do Arqueano. São Paulo, 233p. (Tese - Doutorado) - Instituto de Geociências, Universidade de São Paulo.

CARNEIRO, M.A.; TEIXEIRA, W. (1993) Geoquímica e geocronologia dos diques máficos Precambrianos do Complexo Metamórfico Bonfim Setentrional, região meridional do Cráton do São Francisco, Brasil. In: SEMANA DE GEOQUÍMICA, 9./CONGRESSO GEOQUÍMICO DOS PAÍSES DE LÍNGUA PORTUGUESA, 2., Porto, 1993. Memórias. Porto, SBGq, v.3, p.15-16.

CARNEIRO, M.A.; JORDT-EVANGELISTA, H.; TEIXEIRA, W.; CUNHA, E.M. (1994) Tonalito Arqueano com textura ígnea preservada nos terrenos granito-greenstone do Quadrilátero Ferrifero. In: CONGRESSO BRASILEIRO DE GEOLOGIA, 38., Camboriú, 1994. Boletim de Resumos Expandidos. Camboriú, SBG, v.1, p.81-82.

CARNEIRO, M.A.; NOCE, C.M.; TEIXEIRA, W. (1995) Evolução policíclica do Quadrilátero Ferrífero: uma análise fundamentada no conhecimento atual da geocronologia U-Pb e geoquímica isotópica Sm-Nd. Revista da Escola de Minas, v.48, n.3, p.264-273.

CARNEIRO, M.A.; TELXEIRA, W.; NOCE, C.M.; FERNANDES, R.A. (1996) Archean growth processes in the Quadrilatero Ferrifero: A geochronological U-Pb and $\mathrm{Sm}-\mathrm{Nd}$ approach to the Rio das Velhas Event (2780 - $2700 \mathrm{Ma})$. In: SIMPÓSIO DE TERRENOS ARQUEANOS DA PLATAFORMA SUL-AMERICANA. Brasilia. 1996. Anais. Brasília, SBG, p. 59-60.

JORDT-EVANGELISTA, H.; ALKMIM, F.F.; MARSCHAK, S. (1993a) Transformações mineralógicas e microestruturais do Granito Mamona (Complexo Metamórfico Bonfim), na 
zona de cisalhamento do contato com o Supergrupo Minas, Quadrilátero Ferrifero, MG. In: SIMPÓSIO NACIONAL DE ESTUDOS TECTÔNICOS, 4., Belo Horizonte, 1993. Anais. Belo Horizonte, SBG Núcleo MG, p.246-250. (Boletim,12)

JORDT-EVANGELISTA, H.; CARNEIRO, M.A.; LINDENBERG, S.F. (1993b) Variações químicas do Granito Mamona (Complexo Metamórfico Bonfim), na zona de cisalhamento do contato com o Supergrupo Minas, Quadrilátero Ferrifero, MG. In: SIMPÓSIO DE GEOLOGIA DE MINAS GERAIS, 7., Belo Horizonte. Anais. Belo Horizonte, SBG Núcleo MG, p.108-111. (Boletim, 12)

MACHADO, N.; CARNEIRO, M.A. (1992) Um Significativo Evento Tectôno-termal de 2,78 Ga no Quadrilátero Ferrifero: Evidências U/Pb a partir do Complexo Metamórfico Bonfim Setentrional. Revista da Escola de Minas, v.45, n.1-2, p.138-139.

RUMBLE, D. (1989) Evidences of fluid flow during regional metamorphism. European Journal of Mineralogy, v.1, p.731-737.

TEIXEIRA, W.; CARNEIRO, M.A.; NOCE, C.M.; MACHADO, N.; SATO, K.; TAYLOR, P.N. (1996) $\mathrm{Pb}, \mathrm{Sr}$ and $\mathrm{Nd}$ isotope constraints on the Archean evolution of gneissicgranitoid complexes in the southern São Francisco Craton, Brasil. Precambrian Research, v.78, p.151-164. 